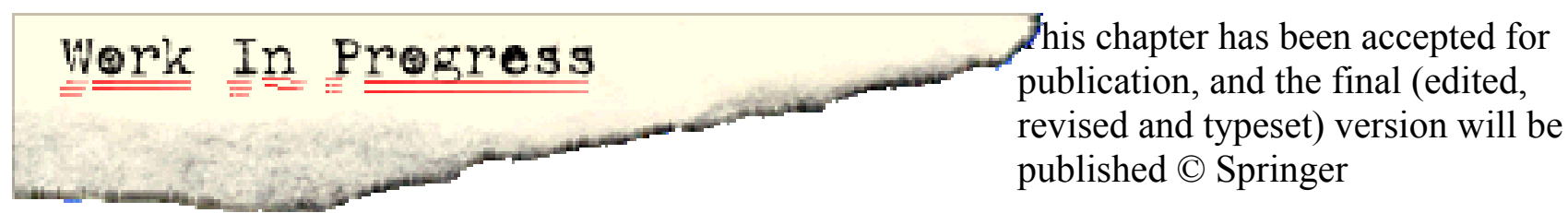

In Marion Myhill and Rupert Maclean (eds) forthcoming 2016

International Handbook on Life in Schools and Classrooms: Past, present and future visions Springer

\title{
Developing learning-centred classrooms and schools
}

Chris Watkins

Reader in Education at Institute of Education, University of London, and independent project leader

\section{Abstract}

This chapter examines the issues and processes in developing more explicit focus on learning in classrooms and schools. It brings together the author's experience of development projects in England and international research. It starts by examining the major forces which have kept classrooms teacher-centred for 5,000 years, moves on to suggest some important starting points for the journey from teacher-centred to learner-centred classrooms, and then identifies the sort of language for learning which will go on to develop learning-centred classrooms. Also considered are the ways in which teachers can be learners themselves, and how the culture of a learning-centred school is created and maintained. Positive effects on pupils' engagement, motivation and attainment are summarised. 36 references.

\section{Keywords}

Learning. Classroom. Change. Agency. Learning orientation. Classroom culture. School culture

\section{Table of Contents}

Introduction and context

Starting the journey

Changing the classroom

The language of learning

Teachers make the change

The learning-centred school

Effects

Conclusion

References

\section{Introduction and context}

One of the most curious things about life in classrooms and schools is how little it focuses on learning. Since classrooms appeared on this planet 5,000 years ago they have been characterised by teacher-driven activity systems. In those Sumerian classrooms where boys were learning cuneiform writing, the teacher inscribed syllables into the first rows of tablets of clay, the boys then had to inscribe their version, at which the teacher corrected their attempt, turned the tablet over and did some more. That form of relationship is described as the IRE cycle: Initiation - Response - Evaluation and research of the last 
fifty years continues to find it as a dominant pattern in current classrooms (Bellack et al 1966; Cazden 2001).

Another puzzle about classrooms is how much they stay the same. Despite changes in rhetoric over decades and centuries, the dominant patterns return to reflect long-standing and dominant cultural beliefs: "teaching is telling, learning is listening, knowledge is subject matter taught by teachers and found in books" (Cuban, 1993). Even across the varying country cultures of our world, patterns of classroom interaction are so similar that a video study found no one country was different on all the aspects observed (Hiebert et al 2003). And in recent decades in UK, the introduction of National Curriculum, national strategies and controlling inspection has led the patterns of classroom interaction to become even more teacher-centred (Galton et al., 1999).

The persistence of such simple ways of running classrooms perhaps reflects the lack of widespread understanding that classrooms are one of the most complex situations on the planet. Doyle $(1986,1990)$ helped us to see that classrooms are busy, public places and classroom events are multidimensional, simultaneous and unpredictable. Another insight comes from those who have studied constancy: one element which contributes to things staying the same is the idea in teachers' minds that that the current situation is not ideal but "good enough".

The effects of these patterns on learners is significant. Their experience as learners is hidden. After four decades of studies of classroom learning issues using hidden microphones and video cameras, Nuthall's final (2007) book was given the title "The Hidden Lives of Learners". As he had summarised earlier: "Whether a student learns or not reflects the students' understanding of classroom tasks, management of social relationships, and the extent to which the student shares the cultural understandings and background knowledge of the teacher and other students" (Nuthall, 1999 p. 213).

These introductory points not only explain why the development of learning-centred classrooms might be less widespread than we might expect, but also start to identify some of the issues that have to be addressed in such development.

\section{Starting the journey}

The term journey is used to signify that changing classrooms is not likely to be a simple or single event. In different contexts with different histories and cultures, the process of development is likely to take a different journey. But there are some general patterns and issues.

One of the important first understandings in developing learning-centred classrooms is that teachers would not wish classroom effects to be as described above. One of the early enquiries in developing a focus on learning is to ask your pupils what they mean by the word "learning". When a five year-old answered "Learning is being good and not being naughty", his class teacher was clearly surprised and disappointed, but later reflected "I suppose we've socialised them into schooling and not socialised them into learning". As more voices from her class show, we can expect a range of answers in any group, but the range has been put in a deliberate order here:

Being good and not being naughty

When you go to PE don't make silly noises otherwise you are going to get sad faces When you're sitting on the carpet, listen to the teacher

When Miss is reading a book you have to listen

You have to listen to Miss - every day

Learn to listen to teacher because when you start your work you won't know what

you're doing

Learn to ride on a horse or ride on a donkey

Learning about snooker

Learning to drive a car 
Share toys with other people

Learning's about doing things on your own

That there's something you haven't done before and you're learning it

When you know, that means you've learned it

Learn about some words you don't know

The order used here reflects the development we seek, from "thin" conceptions of learning (compliance, teacher-driven) to richer conceptions (active, collaborative, cognitive etc). And such development can be promoted in primary or secondary school to avoid the situation described by Devlin (2002) about university students, whose "conceptions of learning were essentially quantitative in nature and were at the lower levels of complexity." (p.125)

Having identified the need for such a journey of enrichment, part of the process includes identifying the forces which work against us, so that their negative effects may be spotted and minimised. For the past decade in the context of the school system in England I have been working with teachers on the following three "space invaders" themes which take up the space which we would wish to give to a focus on learning (Watkins, 2003, 2006).

Space Invader 1: Teaching. In recent years, phrases such as "teaching and learning policies" or "teaching and learning strategies" have been used more and more. But close examination suggests that they might better read "teaching and teaching", since the real attention given to learning is minimal. And the phrase is also often pronounced as "teaching'n'learning" rather like "fish'n'chips" — the "and" is almost missed, implying that they simply go together, whereas that small word "and" captures both the challenge and achievement of the teaching profession: to make teaching lead to learning. So it becomes clear that we need a richer articulation between teaching and learning, and this means separating the two before articulating their connection more effectively. Sometimes this is interestingly started by discussing the question "which do you think happens more often: teaching without learning or learning without teaching?". This regularly raises issues about the classroom context in contrast to other contexts, and often leads to clarifications or definitions.

Space Invader 2: Performance. In current times where politicians and policy-makers make schools focus on measurable outcomes of a limited sort, performance comes to be a poor proxy for learning. We have performance tables, performance pay, performance management. And when schools are placed under performance pressure, the risk is that teachers just pass it on into the classroom culture. But performance is not learning, though it may develop from learning. So understanding the connection between performance and learning is crucial. In a review of 100 classroom studies (Watkins 2010), one of the key messages is "a focus on learning can enhance performance, a focus on performance can depress performance" (page 7).

Space Invader 3: Work. This is the word most often heard in the classroom when we listen for the word "learning": "get on with your work", "homework", "have you finished your work?". As Marshall (1988) pointed out "Teachers often assume that if students do their work, learning will occur automatically" (page 12). This discourse can be changed collaboratively by a teacher and class agreeing that every time they seemed about to use the word "work", they would try the word "learning" instead. The change in atmosphere is significant. In a classroom review, one seven year-old put it this way: "Work is something you do for somebody else. Learning is what you do for yourself - and your friends".

This last change emphasises a parallel point for pupils as has already been made for teachers they do not want the current dominant patterns to continue. An illustration comes from a primary school where the headteacher, knowing that dominant cultures are very resilient, gave a whole school assembly announcing that from this day on there was no more work 
in the school: it was all learning. The five year-olds ran back to their classroom to enthusiastically ask their teacher "Is it true?". The fact that even young children can identify the difference that this change of language makes, and are keen for it, is another starting support for change.

\section{Changing the Classroom}

As mentioned above there are many studies giving evidence of constancy in classrooms, and many reform attempts do not change the basic patterns (Payne, 2008). Even when change attempts use the best collaborative and inquiry methods of teacher development, they may be consolidating the focus on teaching rather than learning.

A resolution to this comes from an approach to change called "Appreciative inquiry" (Hammond, 2000; Cooperrider 2003) in which people are invited to inquire into their best experiences, imagine what might be if more of these occurred, innovate by identifying how to get more, and implement changes in this cycle.

Appreciative inquiry could be applied to any aspect of teachers' professional practice or to school practice.

If appreciative inquiry is used to ask teachers to identify their best experiences of learning in classrooms, the results are affirming and enthusing. Having now done this with thousands of teachers, the first observation is that everyone has had such an experience - in whatever role (teacher, student, observer) they have all had direct experience of a classroom which was associated with exceptional learning, and they can identify key elements which created it. Indeed they are eager to talk with each other about those experiences. More than that, when I invite them to indicate the degree to which those classroom experiences reflect key elements from research (outlined below), around $85 \%$ of teachers indicate a high degree of match with the first three. So the research headings can become a consensus for the development agenda.

The four headings which follow were developed from much thinking about research on learning in classrooms (Watkins et al, 2007) and are intended to reflect what we know about environments which can promote effective learners.

From our understanding of learning, learning is:

- an activity of construction,

- handled with (or in the context of) others,

- driven by learner's agency.

Effective learning is all of these at their best, PLUS the monitoring and review of whether approaches and strategies are proving effective for the particular goals and context.

So an effective learner is someone who knows (and acts accordingly) that:

- it's their actions (not other people's) which are crucial for their learning

- interaction with colleagues can be a resource for their learning

- they can plan monitor and review their learning

- they can learn about and experiment with their learning

So the headings - here phrased as questions for the classroom - are:

Active. Are learners invited and helped to:

Plan their approach to any activity, review the activity, make meaning from the experience and think ahead to other situations?

Collaborative. Are learners invited and helped to:

Complete tasks which require higher-order thinking, necessitating something different from 
all, develop their collaborative skills through prompts and review, operate in a range of participant structures?

Learner-driven. Are learners invited and helped to:

View themselves as driving the learning, contribute their own questions, strategies and explanations, choose their challenges, develop their criteria, and assess their progress?

Learning-focused. Are learners invited and helped to:

View themselves as learners, notice their own learning, story and discuss their own experiences of learning, share their best approaches in order to improve learning, review their learning and its progress over time?

The first three of these four headings seem to connect as a cluster. When classrooms are more active, collaborative and learner-driven, they have moved from the dominant teachercentred model, and can be called learner-centred. But they are not yet learning-centred: that is where the fourth heading is crucial. On the journey of development it is necessary for the first phase (teacher-centred towards learner-centred) to have made progress before the second phase (learner-centred towards learning-centred) can happen effectively. This view comes from having noticed many occasions when change towards learning-centred classrooms is rushed and is not effective. On such occasions a language for learning (usually from some external source) is introduced into a classroom, by the teacher, but the students are not yet in a position where their lived identities in that classroom are those of learners: they may still be receivers, performers, workers etc. So their response to this introduction of new language is often "Hello - teacher's been on a course". If learning-centred change is applied to a classroom which does not have a degree of learner-centredness, the change will not stick.

\section{The Language of Learning}

How can we best talk about learning? Is it a matter of "learning styles" or "learning skills"? Bruner (1985) made a very important distinction which helps us see that such approaches reflect a paradigmatic way of understanding - the use of general theories, and formal systems based on categorisation. The contrast is a narrative way of understanding, which is more particular, time-sensitive, and involves human action and intent. And if at the most general level we view learning as the human process of making meaning from experience, then it is crucial to note that the only form of language humans have for relating experience is narrative (Ricoeur, 1984).

Learning is more than experiencing. Simply having an experience is not enough for someone to learn without reflecting upon this experience. And a narrative approach is helpful in building that key element of reflection. As we relate experiences to each other through the medium of stories, we can "rise above" the immediate experience, notice, and create meaning. Activities such as having pupils tell each other the story of some good learning experiences lead to engaged and enriching exchanges - and no conflict. The narrative form communicates the ownership of the experience in such a way that disagreement does not enter.

Here too, appreciative inquiry can play a very constructive role. Asking pupils to give an account of some of their best learning experiences, and developing an analysis from those accounts. Some "scaffolding devices" may help, such as a simple storyboard of three frames: beginning, middle, end, into which pupils draw the situation and then describe in words each frame of the story. Storyboards may have a general or particular theme: examples such as "Some learning I'm proud of", or "My most impressive learning" developing towards more particular themes such as "A time when I learned really well with others" or "A time when I took charge of my learning". When the story is drawn, pupils are invited to distil their own contribution to the process and project it forward by 
completing a prompt such as "I can help myself be proud of my learning by ......" or "I can help myself learn well with others by .......".

Other practices which support the process of narrating and reviewing learning might include the use of learning journals, especially if the classroom has developed use of the metaphor of a journey to talk about learning. When we're on a journey we take a journal to record the highlights.

As the process of storying experiences develops, a richer understanding of learning develops with it. Through the process. learners rise above the particular stories to develop a richer understanding of learning. This also helps them to develop the metacognitive skill in their learning of noticing more about what they are doing while they are doing it. And in the process, a richer understanding of learning in classrooms can develop. This was illustrated in a review conversation with a class of eight year-olds when the teacher prompted "What's the difference between learning and work?". One student replied "I don't think there is a difference, because when you're working as a teacher you can learn from your students".

\section{Teachers make the change}

In UK a recent large development and research project was led by expert pioneers in "Assessment for Learning", but perhaps in recognition of the evidence that this concept had been distorted by the 'space invaders' in around $80 \%$ of classrooms (Marshall and Drummond, 2006) they called the project "Learning How to Learn" (James et al, 2007). This team investigated what had actually helped those teachers where a learningcentred classroom had developed. Their questionnaire offered a range of the interventions and supports that the project knew were operating: the results showed that the only school practice which helped teachers develop an explicit focus on learning in their classrooms was inquiry (Pedder, 2006).

The message here is in direct contrast to the packaging of classroom change - it indicates that schools as organisations have to treat their teachers as learners too. Packages are likely to revert to teacher-centred patterns of classrooms. For decades, people who have developed learning-centred classrooms have found that other people come along, package the developments, and in the process package surface procedures rather than the principles of learning. As one of the earliest writers to notice this put it: "Some modifications so depart from the original philosophy that they can be termed 'lethal mutations'" (Haertel cited in Brown and Campione 1996, page 292).

If we treat teachers as learners, then staff development activities for teachers should display the same characteristics as were listed above for effective learning in classrooms: active, collaborative, learner-driven, learning-focussed. When these processes are in place teachers start to make changes in their classrooms which are against the grain of the dominant patterns. The power and responsibility shifts, the view of learning enriches, and teachers begin to experience important changes that have been identified in the literature (Weimer 2013).

Part of the journey is that teachers find their predictions about possible negative trends are not founded. Classroom behaviour does not become a problem, and (as outlined in a later section) the results certainly do not go down as feared. But for teachers to be effective on their own learning journey, their school as an organisation needs to support. 


\section{The learning-centred school}

The learning-centred school is a rare place and quietly striking. The students are composed and engaged - with each other, with their teachers and with their products. The teachers are thoughtful learners too. So how is such an organisation created?

Two key elements strike me: the focus on learning for all and a well-developed awareness of culture. In a learning-centred school it has become a kernel activity to talk about learning - one's own learning, no matter what one's role in the organisation may be. School leaders in such schools talk about their own learning journeys - in appropriate ways to their colleagues and to their students. They also initiate conversations and appreciative reviews of how everyone else's learning is going. Leadership is seen as an aspect of many people's roles in different contexts. This is described as "distributed leadership" and the evidence is clear: "School leadership has a greater influence on schools and students when it is widely distributed" (Leithwood Harris \& Hopkins, 2008 page 27).

In learning-centred schools, to lead means to support the learning culture. Such schools recognise that classrooms and schools are at their best when they are in charge of themselves and encouraging the same in others. So the sense of agency, which is such a key element of self-regulated learning at the individual level, also characterises the other levels of the organisation, the classroom and the school (Watkins, forthcoming).

Learning-centred schools have moved away from the dominant stereotype, and the evidence is that schools which make this "second order change" (in other words think differently about their task, and take actions which are a departure from the normative behavior in the environment) do so by leading the culture of learning. And they get better results (Taylor 2010).

The context for such schools matters, and they may have to find themselves working explicitly to counter the forces from the wider context, if those forces represent the 'space invaders' of teaching, performance and work. Currently, in countries where politicians exert a controlling influence on schools, learning-centred schools have to be effective in driving their own agenda rather than being driven from the outside. In the current context of England, schools that are learning-centred will remain a minority because the current pattern of forces suits the interests of the powers that be. In countries such as Singapore, where the Ministry leads a project "Teach Less, Learn More", there might be improved conditions for learning-centred schools to develop. In Thailand, where the central government has mandated a more learner-centred approach (Phungphol, 2005), the culture of leadership at school level is shown to be crucial in making this a success (Hallinger and Bryant, 2013).

\section{Effects}

When classrooms become more learning-centred, a range of positive changes follow. I include here some illustrative comments from school development projects, alongside some findings from research projects (including research in USA where the term learnercentred incorporates some elements of the metacognitive learning about learning which characterise what has been called learning-centred in this chapter).

A large meta-analysis, bringing together the findings of 119 research studies concluded "Overall, learner-centered teacher variables have above-average associations with positive student outcomes" and are "above average compared with other educational innovations for cognitive and especially affective and behavioral outcomes" (Cornelius-White, 2007 page 134).

Certainly classroom teachers report "I have seen a massive improvement in the class's motivation to learn and their behaviour. In fact, I am no longer 'managing' behaviour! Children are motivated, engaged and responsible". Improved engagement has also been 
found at later age levels: a study of high school students who are at risk of dropping out of school concluded "a learner-centred environment yields significantly higher achievement scores and a somewhat higher internal motivational orientation" (Alfassi, 2004 page 1).

The change in motivational orientation is central. Students increase their learning orientation, in which they seek to develop their competence by acquiring new skills and mastering new situations. When a headteacher says "The children are more self-motivated, active, pushing themselves to achieve more", they are making the connection with the fact that learners who are experiencing agency are also more motivated to learn. A study of a large sample of middle and high school students assessed the connections with students seeing their teachers as using learner-centred practices in the classroom, and said that most importantly, individual perceptions of learner-centered teaching practices positively predicted learning orientation (Meece et al, 2003).

Learning orientation is strongly developed by the increase in learning talk in the classroom. Teachers report "Children are more able to talk reflectively about their learning; when they learn best and what helps them to achieve this: they can identify how they learn best at school and beyond the classroom". Others say that students "are happy to celebrate their mistakes and how they've learnt from them". And yet others report that the reference to learning becomes heard more from pupils in the classroom: "We're learning from Emily now" "Let's put into practice what we just learnt from Dylan".

When engagement and motivation become learning-centred, attainment improves as a bonus. Schools report their best ever performance in national tests, including those schools who were well below national average. This reflects research in other countries, where national samples showed that as teachers' classroom practices became more learnercentered, academic performance increased as assessed by both teacher classroom grades and standardized achievement tests (Weinberger and McCombs, 2001).

An extra bonus in performance measures is increased equity. Classroom teachers report previously underachieving children are amongst those progressing at twice the national average. And schools in very disadvantaged areas have doubled the proportion of pupils who achieve nationally prescribed levels in tests so that these schools now "perform" above the national average. On other dimensions of potential disadvantage, research in USA on minority groups showed that "minorities in schools and classrooms with higher learner-centered orientations not only have test scores statistically equal of those from their white peers, but also that students in learner-centered schools have higher scores in the non-traditional measures, including tolerance and openness to diversity" (Salinas and Garr 2009).

The only intervention which achieves both equity and excellence is one that is learning-centred.

In terms of the headings used in this chapter to describe the phases in the journey, the link with performance can be summarised as:

- Teacher centred classrooms create a culture which tests the motivation of predictable groups of learners to the limit, and a pattern of performance in which the long-standing patterns of school achievement remain.

- Learner-centred classrooms create a more engaging culture for a wider range of learners but may not generate a widely shared wish to achieve

- Learning-centred classrooms create an engaging culture and an identity as learners for all their participants. Enhanced thinking, challenge and agency can lead to pupils making double the progress in measured performance. 


\section{Conclusion}

Has this chapter added anything new? With reference to the book title: "Life in Schools and Classrooms: Past, present and future visions" I see the development of learning-centred classrooms as a past, present and future vision, at least for the last four centuries. As Jan Amos Comenius (1592-1670) put it "Let the beginning and the end of our didactics be: seek and find the methods where the teacher teaches less but they who sit in the desks learn more. Let schools have less rush, less antipathy and less vain effort, but more well-being, convenience and permanent gain." The Great Didactic, 1632. Nonetheless I recognise it has been a minority vision, held back by other cultural dynamics.

In this chapter I hope to have indicated some current processes by which the vision becomes a reality. That provides a future possibility of the vision being realised more widely.

\section{References}

Alfassi M (2004) Effects of a learner-centred environment on the academic competence and motivation of students at risk. Learning Environments Research 7:1-22

Bellack AA, Kliebard HM, Hyman RT, Smith FL (1966) The Language of the Classroom. Teachers' College Press, New York

Brown AL, Campione JC (1996) Psychological theory and the design of innovative learning environments: on procedures, principles, and systems. In: Schauble L, Glaser R (eds) Innovations In Learning: New Environments for Education. Lawrence Erlbaum Associates, Hillsdale NJ,

Bruner JS (1985) Narrative and paradigmatic modes of thought. In: Eisner E (ed) Learning and Teaching the Ways of Knowing. 84th Yearbook of the National Society for the Study of Education, Part 2. University of Chicago Press, Chicago,

Cazden CB (2001) Classroom Discourse: The Language of Teaching and Learning. second edition edn. Heinemann Educational, London

Cooperrider D, Whitney D, Stavros JM (2003) Appreciative Inquiry Handbook. Lakeshore publishers/McGraw Hill Europe, Bedford Heights $\mathrm{OH}$

Cornelius-White J (2007) Learner-centered teacher-student relationships are effective: a meta-analysis. Review of Educational Research 77 (1):113-143

Cuban L (1993) Computers meet classroom - classroom wins. Teachers College Record 95 (2):185-210

Devlin M (2002) Taking responsibility for learning isn't everything: a case for developing tertiary students' conceptions of learning. Teaching in Higher Education 7 (2):125-138

Doyle W (1986) Classroom organization and management. In: Wittrock MC (ed) Handbook

of Research on Teaching. 3rd edition edn. Macmillan, New York,

Doyle W (1990) Classroom knowledge as a foundation for teaching. Teachers College Record 91 (3):347-360

Galton M, Hargreaves L, Comber C, Wall D, Pell T (1999) Changes in patterns of teacher interaction in primary classrooms: 1976-96. British Education Research Journal 25 (1):23-37 Hallinger P, Bryant DA (2013) Synthesis of findings from 15 years of educational reform in Thailand: lessons on leading educational change in East Asia. International Journal of Leadership in Education (ahead-of-print):1-20

Hammond SA (2000) The Thin Book of Appreciative Inquiry. www.thinbook.com, Bend OR Hiebert J, Gallimore R, Garnier H, Givvin KB, Hollingsworth H, Jacobs J, Chui AM-Y, Wearne D, Smith M, Kersting N, Manaster A, Tseng E, Etterbeek W, Manaster C, Gonzales P, Stigler J (2003) Teaching Mathematics in Seven Countries: Results From the TIMSS 
1999 Video Study. U.S. Department of Education National Center for Education Statistics, Washington DC

James M, McCormick R, Black P, Carmichael P, Drummond M-J, Fox A, MacBeath J, Marshall B, Pedder D, Procter R (2007) Improving learning how to learn: Classrooms, schools and networks. Routledge,

Leithwood K, Harris A, Hopkins D (2008) Seven strong claims about successful school leadership. School Leadership and Management 28 (1):27-42

Marshall B, Drummond MJ (2006) How teachers engage with Assessment for Learning: lessons from the classroom. Research Papers in Education 21 (2):133-149

Marshall HH (1988) Work or learning: implications of classroom metaphors. Educational Researcher 17 (9):9-16

Meece JL, Herman P, McCombs BL (2003) Relations of learner-centered teaching practices to adolescents' achievement goals. International Journal of Educational Research 39 (45):457-475

Nuthall G (1999) Learning how to learn: the evolution of students' minds through the social processes and culture of the classroom. International Journal of Educational Research 31 (3):141-256

Nuthall G (2007) The Hidden Lives of Learners. NZCER, Wellington NZ

Payne CM (2008) So Much Reform, So Little Change: The Persistence of Failure in Urban Schools. Harvard Education Press, Boston

Pedder D (2006) Organizational conditions that foster successful classroom promotion of Learning How to Learn. Research Papers in Education 21 (2):171-200

Phungphol $Y$ (2005) Learner-centered teaching approach: A paradigm shift in Thai education. ABAC journal 25 (2):5-16

Ricoeur P (1984) Time and narrative. Volume I (trans: McLaughlin K, Pellauer D). University of Chicago Press, Chicago

Salinas MF, Garr J (2009) Effect of Learner-Centered Education on the Academic Outcomes of Minority Groups. Journal of instructional Psychology 36 (4):226-237

Taylor RT (2010) Leadership to improve student achievement: Focus the culture on learning. Journal of Scholarship and Practice 7 (1):10-23

Watkins C (2003) Learning: a sense-maker's guide. Association of Teachers and Lecturers, London

Watkins C (2005) Classrooms as Learning Communities: what's in it for schools.

FalmerRoutledge, London

Watkins C (2006) When teachers reclaim learning. Forum for promoting 3-19 comprehensive education 48 (2 Summer):121-129

Watkins C (2010) Learning, Performance and Improvement. Research Matters series. Institute of Education, International Network for School Improvement, London

Watkins C (forthcoming) We need to get Three As- Appropriate Agency for All. In: Norman $G$ (ed) Matthew Moss High School: a learning-centred school. loE Press, London,

Watkins C, Carnell E, Lodge C (2007) Effective Learning in Classrooms. Paul Chapman/Sage, London

Weimer M (2013) Learner-centered Teaching: Five key changes to practice. second edn. Josssey-Bass, San Francisco

Weinberger E, McCombs BL (2001) The Impact of Learner-Centered Practices on the Academic and Non-Academic Outcomes of Upper Elementary and Middle School Students. Paper presented at the Annual meeting of the American Educational Research Association, Seattle, 


\section{Bio-data - up to 150 words}

Chris Watkins is a reader in education at the University of London Institute of Education, and an independent project leader with schools.

In 1999 he founded the MA in Effective Learning and since that time has been involved in projects with a range of schools and local authorities on learning about learning, effective learning, classroom learning, teachers' learning and school learning. This work culminates in the idea of classrooms as learning communities.

He has recently been leading projects on developing learning-centred classrooms and schools around England, and with individual schools in London.

www.chriswatkins.net $\quad$ www.ioe.ac.uk/people/chriswatkins

http://ioe.academia.edu/ChrisWatkins 